\title{
Green Tea: Conventional Facts and its Frontier Prospect on Health- A review
}

\author{
Swarup Kumar Kundu1,a,, , M. Sohidullah ${ }^{3, c,}$, Shonkor Kumar Das ${ }^{2, b}$ \\ ${ }^{1}$ Department of Anatomy and Histology, Faculty of Veterinary, Animal and Biomedical Sciences, Khulna Agricultural University, Khulna, \\ Bangladesh \\ ${ }^{2}$ Department of Anatomy and Histology, Faculty of Veterinary Science, Bangladesh Agricultural University, Mymensingh-2202, \\ Bangladesh \\ ${ }^{3}$ Department of Microbiology and Public Health, Faculty of Veterinary, Animal and Biomedical Sciences, Khulna Agricultural University, \\ Khulna, Bangladesh \\ *Corresponding author

\begin{tabular}{l|l}
\hline A R T I C L E I N F O & A B S T R A C T \\
\hline $\begin{array}{l}\text { Review Article } \\
\text { Received : 20/02/2020 } \\
\text { Accepted : 10/03/2021 }\end{array}$ & $\begin{array}{l}\text { Green tea obtained from the leaves of Camellia sinensis (L.) Kuntze having potential health } \\
\text { benefits. It contains significant amounts of antioxidant and is considered as world healthiest drink. } \\
\text { Polyphenols in tea are thought to exhibits anti-carcinogenic and anti-inflammatory effects. Green } \\
\text { tea catechins acts as immune modulators in immune dysfunction and also play a role in protection } \\
\text { from degenerative diseases. Intake of green tea catechins suppress high fat diet induced obesity, } \\
\text { prevent lipid and glucose metabolism disorders and reduce risk of coronary heart disease. Green tea } \\
\text { constituent epigallocatechin-3-gallate (EGCG) is a potential antioxidant that shows protective } \\
\text { effects against photo toxicity and photo carcinogenesis. In vitro animal experiments have suggested } \\
\text { that polyphenols in green tea protect from lung cancer by their antioxidant and antimutagenic } \\
\text { properties. This study chiefly highlights the convenience of green tea on health and propagates its } \\
\text { further prospects. }\end{array}$ \\
$\begin{array}{l}\text { Keywords: } \\
\text { Green tea }\end{array}$ &
\end{tabular}

Conventional facts

Frontier prospect

Health issue

Excellent beverage

\section{Introduction}

The use of herbs in alternative medicine is quite common (Sevindik et al., 2017; Pehlivan et al., 2018; Mohammed et al., 2019). Plants are used with different methods (Mohammed et al., 2020). Green tea is one of the most widely used herbs around the world. In recent times green tea is the most attractive beverage for its significant health benefits (Cabrera et al., 2006). In $17^{\text {th }}$ century green tea was first exported from India to China (Chacko et al., 2010): from that time green has become a traditional medicine in china (Cabrera et al., 2006). Now a day's green tea is cultivated largely in Asia, South America and Africa (Ben and Micheal, 2007). Main catechins in green tea are epicatechin, epicatechin-3-gallate, epigallocatechin and epigallocatechin-3-gallate (EGCG) (Sano et al., 2001). Green tea is considered as health promoting agent for its higher content of major catechins called epigallocatechin3-gallate (EGCG) that exhibit biochemical and pharmacological activities (Siddiqui et al., 2006). It also a main source of caffeine that works on the different systems of body (Cavalli and Tavani, 2016). Green tea intake reduces liver diseases (Jin et al., 2008), cardiovascular diseases and also acts as protective agent against various health disorders (Benelli et al., 2002; Weisburger et al., 2002). Hence, the aim of this present review was to assess the overall effects of green tea consumption on health. 


\section{Composition of Green Tea}

Green tea contains some special Chemical components like: Proteins (15-20\% dry weight), carbohydrates $(5-7 \%$ dry weight), amino acids (1-4\% dry weight) and trace elements (5\% dry weight). It also contains trace amounts of lipids (linoleic and $\alpha$-linolenic acids), vitamins (B, C, E), sterols (stigmasterol), pigments (chlorophyll, carotenoids), xanthic bases (caffeine, theophylline) and volatile compounds (aldehydes, alcohols, esters, lactones, hydrocarbons) (Belitz and Grosch, 1992). Green tea leaves also contains $3-4 \%$ of alkaloids called methylxanthines, such as caffeine, theophylline and theobromine (Graham, 1992).

\section{Medicinal Importance of Green Tea}

Some epidemiological studies suggested the beneficial effects of green tea on human health including anti-obesity, antidiabetic, anticancer, anti-viral, antibacterial and hepatoprotective effects. This findings mainly supported by cell based and animal trial (Suzuki et al., 2012). The medicinal properties of green tea were presented in the following section:

\section{Anti-obesity}

Obesity is now a main headache in our population that causes some weight related complications and also develops lung diseases, diabetes, coronary heart diseases, arthritis, metabolic syndrome etc. (Barnes et al., 2004; Adam-Perrot et al., 2006). Some clinical studies have demonstrated the beneficial role of green tea polyphenols on obesity (Schneider and Segre, 2009; Suliburska et al., 2012; Miyoshi et al., 2015). Green tea causes thermogenesis by polyphenol constituents called catechins that stop the breakdown of norepinephrine. This may increase mitochondrial oxidation, and produce heat. Catechins also impair angiogenesis and inhibit the development of adipose tissue (Han et al., 1999; Dulloo et al., 2000). Recent trials on human indicate that green tea or its extract may decrese body weight gaining by increasing postprandial thermogenesis and fat oxidation (Zamboni et al., 2005).

\section{Anti-diabetic}

Green tea and its extract have thermo genic properties and promote fat oxidation that modify glucose metabolism and prevent type- II diabetes mellitus (Tsuneki et al., 2004; Wu et al., 2004). Green tea constituent's epigallocatechin3-gallate (EGCG) is a potential antioxidant that ameliorates cytokine-induced $\beta$ cell damage and prevents the reduction of islet mass (Song et al., 2003): In a cohort study, among 937 older adults, long term intake of green tea about 1-2 cups/day lower $70 \%$ type-II diabetes mellitus (Panagiotakos et al., 2009).

\section{Anti-cancer}

From some epidemiological studies, green tea extract possesses some beneficial effects against various cancer (Yang et al., 2009; Yang and Wang, 2016). Based on some case-control and cohort studies that were carried out from 1965 to 2008 a review article suggested that green tea consumption reduce the risk of bladder, colon, breast, gastric, lung, kidney, ovarian, pancreatic, and prostate cancers (Yang et al., 2009). European prospective investigation into Cancer and Nutrition study revealed that increased tea intake reduced the risk of developing hepatocellular carcinoma (Bamia et al., 2015). In a subgroup analysis of individuals in Western countries, the consumption of tea reduced the risk of bladder cancer (Zhang et al., 2015). Italian research group showed that green tea catechins were safe and highly effective for the treatment of premalignant lesions (Bettuzzi et al., 2006). According to Japan Public Health Center-Based prospective study, green tea intake may decrease the risk of advanced prostate cancer (Sawada, 2017). A stratified analysis revealed that green tea had a protective effect against rectal cancer (Chen et al., 2017).

\section{Hepatoprotective}

Liver is one of the key metabolic organs that play a role in metabolism and detoxification process but any disorder of this organ causes serious health problems (Samuel et al., 2012). There are many risk factors for liver diseases. Liver toxicity mainly develops by different types of drug induction (Lee et al., 2005). Different studies observed that green tea helps in lipid metabolism that reduces lipid accumulation in liver. Green tea consumption also offers protective action against malignant change by its polyphenolic antioxidants (Sing et al., 2011). Histological and histochemical changes of liver induced by cyclophosphamide may improve by green tea extract consumption at a dose $50 \mathrm{mg} / \mathrm{kg} /$ day (Ali, 2018).

\section{Others}

Green tea can be employed as supplement for probiotics milk (Najgebauer-Lejko, 2014). Tea leaves produce polyphenolic compounds that involved in protective action against pathogens like bacteria, viruses, fungi and insects (Friedman, 2007). Aqueous extraction of green tea reduce viable fungal cells (Antunes et al., 2015). Green tea polyphenols are beneficial for the prevention of dental carries (Sakanaka, 1997). Green tea extracts also having the capacity of lowering cholesterol level (Bursill et al., 2007; Rehrah et al., 2007).

\section{Frontier Prospects Regarding Health Issues}

We know green tea is a natural diuretic that possess many beneficial effects on health as well as show a promising future as popular drink (Mahmood et al., 2017). But some conflicting results also have been reported. Major constituent of green tea is caffeine. So, excess intake of green tea may cause nausea. Tannins present in green tea that interferes iron absorption causes iron deficiency anemia. Other side effects of excess green tea consumption are vomiting, abdominal pain, loss of appetite, dyspepsia and diarrhea. Excess green tea intake also causes insomnia, vertigo, tremors and psychomotor agitation (Nawab and Farooq, 2015). Oral administration of high doses of green tea extracts causes toxicity (Isbrucker et al., 2006). High doses of green tea catechins associated with prostate cancer (Gontero et al., 2015). Daily intake of green tea causes slight increase in hypertension risk (Chei et al., 2018). Drinking of extreme amounts of green tea (more than five cups /day) can cause urination and lead to dehydration and 
electrolyte disproportion. Dehydration can also leads to lethargy, headaches, changed heart rate and distress. So excess green tea intake in a day should be avoided (Nawab and Farooq, 2015).

\section{Conclusion}

Green tea is an excellent worldwide accepted popular beverage. It contains useful ingredients for the improvement of our health condition but excess consumption can show some adverse effects. So people should aware of this regard.

\section{References}

Adam-Perrot A, Clifton P, Brouns F.2006. Low-carbohydrate diets: nutritional and physiological aspects. Obesity reviews, $7(1): 49-58$.

Ali AH. 2018. Hepatoprotective effect of green tea extract against cyclophosphamide induced liver injury in Albino rats. Forensic Medicine and Anatomy Research, 6(2):11-9.

Antunes DP, Salvia AC, de Araújo RM, Di Nicoló R, Koga Ito CY, de Araujo MA. 2015. Effect of green tea extract and mouthwash without alcohol on Candida albicans biofilm on acrylic resin. Gerodontology, 32(4):291-5.

Bamia C, Lagiou P, Jenab M, Trichopoulou A, Fedirko V, Aleksandrova K, Pischon T, Overvad K, Olsen A, Tjønneland A, Boutron-Ruault MC. 2015. Coffee, tea and decaffeinated coffee in relation to hepatocellular carcinoma in a $\mathrm{E}$ uropean population: Multicentre, prospective cohort study. International journal of cancer, 136(8):1899-908.

Barnes PM, Powell-Griner E, McFann K, Nahin RL. 2004. Complementary and alternative medicine use among adults: United States, 2002. InSeminars in integrative medicine, pp. 54-71.

Belitz HD, Grosch W. 1992. Química de los alimentos.

Ben EW, Michael W. 2007. Medicinal plants of the world. Shinilbooks; Timber Press Inc.: Portland, OR, USA.

Benelli R, Venè R, Bisacchi D, Garbisa S, Albini A. 2002. Antiinvasive effects of green tea polyphenol epigallocatechin-3gallate (EGCG), a natural inhibitor of metallo and serine proteases. Biological Chemistry, 383(1):101-5.

Bettuzzi S, Brausi M, Rizzi F, Castagnetti G, Peracchia G, Corti A. 2006. Chemoprevention of human prostate cancer by oral administration of green tea catechins in volunteers with highgrade prostate intraepithelial neoplasia: a preliminary report from a one-year proof-of-principle study. Cancer research, 66(2):1234-1240.

Bursill CA, Abbey M, Roach PD. 2007. A green tea extract lowers plasma cholesterol by inhibiting cholesterol synthesis and upregulating the LDL receptor in the cholesterol-fed rabbit. Atherosclerosis, 193(1):86-93.

Cabrera C, Artacho R, Giménez R. 2006. Beneficial effects of green tea- a review. Journal of the American College of Nutrition, 25(2):79-99.

Cavalli L, Tavani A. 2016. Coffee consumption and its impact on health. In Beverage Impacts on Health and Nutrition, pp. 2947.

Chacko SM, Thambi PT, Kuttan R, Nishigaki I. 2010. Beneficial effects of green tea: a literature review. Chinese medicine, $5(1): 13$.

Chei CL, Loh JK, Soh A, Yuan JM, Koh WP. 2018. Coffee, tea, caffeine, and risk of hypertension: The Singapore Chinese Health Study. European journal of nutrition, 57(4):13331342.

Chen Y, Wu Y, Du M, Chu H, Zhu L, Tong N, Chen J. 2017. An inverse association between tea consumption and colorectal cancer risk. Oncotarget, 8(23):37367.
Dulloo AG, Seydoux J, Girardier L, Chantre P, Vandermander J. 2000. Green tea and thermogenesis: interactions between catechin-polyphenols, caffeine and sympathetic activity. International journal of obesity, 24(2):252-258.

Friedman M. 2007. Overview of antibacterial, antitoxin, antiviral, and antifungal activities of tea flavonoids and teas. Molecular nutrition \& food research, 51(1):116-134.

Gontero P, Marra G, Soria F, Oderda M, Zitella A, Baratta F, Frea B. 2015. A randomized double-blind placebo controlled phase I-II study on clinical and molecular effects of dietary supplements in men with precancerous prostatic lesions. Chemoprevention or "chemopromotion"? The Prostate, 75(11): 1177-1186.

Graham HN. 1992. Green tea composition, consumption, and polyphenol chemistry. Preventive medicine, 21(3):334-350.

Han LK, Takaku T, Li J, Kimura Y, Okuda H. 1999. Anti-obesity action of oolong tea. International journal of obesity, 23(1):98-105.

Isbrucker RA, Edwards JA, Wolz, E, Davidovich A, Bausch J. 2006. Safety studies on epigallocatechin gallate (EGCG) preparations. Part 2: dermal, acute and short-term toxicity studies. Food and chemical toxicology, 44(5):636-650.

Jin X, Zheng RH, Li YM. 2008. Green tea consumption and liver disease: a systematic review. Liver international, 28(7): 990-996.

Lee HS, Won NH, Kim KH, Lee H, Jun W, Lee KW. 2005. Antioxidant effects of aqueous extract of Terminalia chebula in vivo and in vitro. Biological and Pharmaceutical Bulletin, 28(9):1639-1644.

Mahmood MS, Mártinez JL, Aslam A, Rafique A, Vinet R, Laurido C, Ali S. 2016. Antiviral effects of green tea (Camellia sinensis) against pathogenic viruses in human and animals (a mini-review). African Journal of Traditional, Complementary and Alternative Medicines, 13(2):176-184.

Miyoshi N, Pervin M, Suzuki T, Unno K, Isemura M, Nakamura Y. 2015. Green tea catechins for well-being and therapy: Prospects and opportunities. Bot. Targets Ther, 5:85-96.

Mohammed FS, Pehlivan M, Sevindik M. 2019. Antioxidant, antibacterial and antifungal activities of different extracts of Silybum marianum collected from Duhok (Iraq). International Journal of Secondary Metabolite, 6(4): 317-322.

Mohammed FS, Günal S, Şabik AE, Akgül H, Sevindik M. 2020. Antioxidant and Antimicrobial activity of Scorzonera papposa collected from Iraq and Turkey. Kahramanmaraş Sütçü İmam Üniversitesi Tarım ve Doğa Dergisi, 23(5): 1114-1118.

Najgebauer-Lejko D. 2014. Effect of green tea supplementation on the microbiological, antioxidant, and sensory properties of probiotic milks. Dairy science \& technology, 94(4):327-339.

Nawab A, Farooq N. 2015. Review on green tea constituents and its negative effects. J Pharm Innov, 4(1):21-24

Panagiotakos DB, Lionis C, Zeimbekis A, Gelastopoulou K, Papairakleous N, Das UN, Polychronopoulos E. 2009. Longterm tea intake is associated with reduced prevalence of (type 2) diabetes mellitus among elderly people from Mediterranean islands: MEDIS epidemiological study. Yonsei medical journal, 50(1):31-38.

Pehlivan M, Mohammed FS, Sevindik M, Akgul H. 2018. Antioxidant and oxidant potential of Rosa canina. Eurasian Journal of Forest Science, 6(4): 22-25.

Rehrah D, Ahmedna M, Yu J, Goktepe I, Hurley S, Hanner T, Rao-Patel A. 2007. Enhanced cholesterol-and triglyceridelowering effect of West African green tea. Journal of the Science of Food and Agriculture, 87(7):1323-1329.

Sakanaka S. 1997. Green tea polyphenols for prevention of dental. Chemistry and applications of green tea, 87 .

Samuel AJSJ, Mohan S, Chellappan DK, Kalusalingam A, Ariamuthu S. 2012. Hibiscus vitifolius (Linn.) root extracts shows potent protective action against anti-tubercular drug induced hepatotoxicity. Journal of ethnopharmacology, 141(1):396-402. 
Sano M, Tabata M, Suzuki M, Degawa M, Miyase T, MaedaYamamoto M. 2001. Simultaneous determination of twelve tea catechins by high-performance liquid chromatography with electrochemical detection. Analyst, 126(6):816-820.

Sawada N. 2017. Risk and preventive factors for prostate cancer in Japan: The Japan Public Health Center-based prospective (JPHC) study. Journal of epidemiology, 27(1):2-7.

Schneider C, Segre T. 2009. Green tea: potential health benefits. American family physician, 79(7):591-594.

Sevindik M, Akgul H, Pehlivan M, Selamoglu Z. 2017. Determination of therapeutic potential of Mentha longifolia ssp. longifolia. Fresen Environ Bull, 26(7): 4757-4763.

Siddiqui IA, Adhami VM, Saleem M, Mukhtar H. 2006. Beneficial effects of tea and its polyphenols against prostate cancer. Molecular nutrition \& food research, 50(2):130-143.

Sing MF, Yang WS, Gao S, Gao J, Xiang YB. 2011. Epidemiological studies of the association between tea drinking and primary liver cancer: a meta-analysis. European Journal of Cancer Prevention, 20(3):157-165.

Song EK, Hur H, Han MK. 2003. Epigallocatechin gallate prevents autoimmune diabetes induced by multiple low doses of streptozotocin in mice. Archives of pharmacal research, 26(7):559-563.

Suliburska J, Bogdanski P, Szulinska M, Stepien M, PupekMusialik D, Jablecka A. 2012. Effects of green tea supplementation on elements, total antioxidants, lipids, and glucose values in the serum of obese patients. Biological trace element research, 149(3):315-322.
Suzuki Y, Miyoshi N, Isemura M. 2012. Health-promoting effects of green tea. Proceedings of the Japan Academy, Series B, 88(3):88-101.

Tsuneki H, Ishizuka M, Terasawa M, Wu JB, Sasaoka T, Kimura I. 2004. Effect of green tea on blood glucose levels and serum proteomic patterns in diabetic $(\mathrm{db} / \mathrm{db})$ mice and on glucose metabolism in healthy humans. BMC pharmacology, 4(1):18.

Weisburger JH, Chung FL. 2002. Mechanisms of chronic disease causation by nutritional factors and tobacco products and their prevention by tea polyphenols. Food and Chemical Toxicology, 40(8):1145-1154.

Wu LY, Juan CC, Hwang LS, Hsu YP, Ho PH, Ho LT. 2004. Green tea supplementation ameliorates insulin resistance and increases glucose transporter IV content in a fructose-fed rat model. European journal of nutrition, 43(2):116-124.

Yang CS, Wang H. 2016. Cancer preventive activities of tea catechins. Molecules, 21(12): 1679.

Yang CS, Wang X, Lu G, Picinich SC. 2009. Cancer prevention by tea: animal studies, molecular mechanisms and human relevance. Nature Reviews Cancer, 9(6):429-439.

Zamboni M, Mazzali G, Zoico E, Harris TB, Meigs JB, Di Francesco V, Bosello O. 2005. Health consequences of obesity in the elderly: a review of four unresolved questions. International journal of obesity, 29(9):1011-1029.

Zhang YF, Xu Q, Lu J, Wang P, Zhang HW, Zhou L, Zhou YH. 2015. Tea consumption and the incidence of cancer: a systematic review and meta-analysis of prospective observational studies. European Journal of Cancer Prevention, 24(4):353-362. 